\title{
Cancer patients' experiences of care related to pain management before and after palliative care referral
}

B. BOSTRÖM, RN, RNIC, RNT, PHD, School of Social and Health Sciences, Halmstad University, Halmstad, M. SANDH, RN, RNAN, RNT, MNSC, School of Social and Health Sciences, Halmstad University, Halmstad, D. LUNDBERG, MD, PHD, FRCA, PROFESSOR, Department of Anaesthesiology and Intensive Care, Lund University, University Hospital, Lund \& B. FRIDLUND, RN, RNAN, RNT, PHD, PROFESSOR, School of Social ↔ Health Sciences, Halmstad University, Halmstad, Sweden and Department of Nursing, Lund University, Lund, Sweden

BOSTRÖM B., SANDH M., LUNDBERG D., FRIDLUND B. (2004) European Journal of Cancer Care 13, 238245

Cancer patients' experiences of care related to pain management before and after palliative care referral

Pain is the main problem for patients with cancer referred to palliative care (PC). Pain management in PC requires a multidimensional approach. A questionnaire was used to determine cancer patients' experiences of care related to pain management, before and after being referred to PC, and to also discover possible correlations between pain control and other aspects of care. Seventy-five consecutive patients from two PC teams were included in the study. The patients had experienced a statistically significant $(P<0.01)$ improvement in care after being referred to PC, despite the fact that pain control had not been optimized. Patients' description of 'pain control' after being referred to PC had a statistically significant correlation with their 'feeling of security' and 'continuity of care' throughout the same period. The conclusion is that care provided in PC is vital to successful pain management. Pain control depends not only on analgesics but also on many other aspects of care provided by the nurse. Continuity of care and the opportunity to talk increases the patients' feeling of security, which is also of utmost importance to successful pain management.

Keywords: cancer-related pain, dimensions of pain, pain management, palliative care.

\section{INTRODUCTION}

Pain is permanent or frequent for over $60 \%$ of patients with advanced cancer (Thomason et al. 1998), and more than $90 \%$ of patients who die as a result of cancer suffer from pain in the final phase of life. For the patient, pain may be interpreted as a constant reminder of cancer. The full understanding of pain and pain management requires an examination of the physiological, sensory, affective, cognitive, behavioural, and socio-cultural dimensions

Correspondence address: Barbro Boström, School of Social and Health Sciences, Halmstad University, PO Box 823, S-301 18 Halmstad, Sweden (Tel: +46 35 167405; e-mail: Barbro.Bostrom@hos.hh.se).

Accepted 14 October 2003

European Journal of Cancer Care, 2004, 13, 238-245 contributing to pain (Ahles et al. 1983; McGuire 1992; Ferrell et al. 1994; Strang 1998). Pain assessment based on an accurate report from the patient, including these various dimensions, is the cornerstone of pain management. This must be followed by a care and treatment plan, once again in close consultation with the patient (Boström et al. 1997; Thomason et al. 1998). The World Health Organization (1996) has published guidelines for effective pain relief based on the use of appropriate drugs in correct doses at correct intervals. In addition, The Swedish Nurse Organization (1999) has published guidelines for the use of non-drug interventions.

Palliative care $(\mathrm{PC})$ includes all aspects of caring for patients who no longer respond to active treatment. The primary function of PC is to maintain patients' quality of life until the time of death. A pain-related problem is the key reason for most patients' referrals to PC (Ellershaw 
et al. 1995). Therefore, the physiological, sensory, affective, cognitive, behavioural, and socio-cultural dimensions contributing to pain influence the range of objectives embodied in PC such as: control of symptoms, support to the family, improved communication and coordination, spiritual care, and choice and control over care (Mino 1999). However, despite being referred to a PC unit more than $30 \%$ of patients with advanced cancer report that they suffer from unacceptably severe pain (McMillan 1996; Twycross et al. 1996). There has been a rapid growth in the number of PC services, for patients with advanced cancer, provided by a varying composition of care providers (Chochinov \& Kristjanson 1998; Hearn \& Higginson 1998).

The responsibility of the nurse is fundamental in PC, as the nurse is the link between the patient, other care providers and the patient's family (The Swedish National Board of Health and Welfare 2001). The nurse's role within pain management is of great importance. The nurse should encourage the patient to be an active participant in their care and in discussing goals for pain control and intervention plans (Ashby \& Dowding 2001).

The ethical and methodological problems specifically affecting evaluation of PC have been thoroughly discussed (McWhinney et al. 1994), implying that there is a need to adopt a broad approach reflecting the complexities of PC (Ingleton et al. 1997; Mino 1999; Abu-Saad 2000). It may be difficult to select variables in order to assess the outcome of PC (Rink et al. 1997). One important outcome variable should be management of patients' pain - directly from the point of diagnoses (McMillan 1996; Strang 1998). When evaluating pain management in PC patients' opinions are vital and attention should be given to both the care process and the outcome variables (Ingleton et al. 1997; Hearn \& Higginson 1999; Newbury 2002).

The aim of this study was to determine cancer patients' experiences of care related to pain management, before and after being referred to a PC team. A further aim was to find correlations between pain control and other aspects of care.

\section{METHODS}

\section{Design and setting}

A descriptive study design focusing on PC evaluation was performed in a county of southwest Sweden with a catchment area of 370000 inhabitants. The study was approved by the Committee of Ethics in Medical Investigations, Universities of Lund and Göteborg, Sweden.

\section{Palliative care}

Palliative care was performed by two teams from different organizations, each being associated with a hospital. The teams provided a home-care service including services to inpatients and consultancy-based services available to hospital staff and the community. Patients were referred to PC after consultation with their usual physician either by a nurse caring for the patient or by a patient's relative. The most common reasons for requesting PC were painassociated problems. The independent PC objectives of the two teams were almost identical: to make an assessment of patients' problems and needs, and to suggest, initiate and perform interventions for relief of pain and other symptoms while preventing negative side-effects of medication. The objective also included continually supporting nurses and physicians in providing a link between the patients, their families and other care providers.

\section{Sample}

A sample of 75 consecutive patients from two hospitalbased PC teams was enrolled. The inclusion criteria were: being orientated to person and place, having no major sensorial defects, able to speak Swedish, over 35 years of age, in need of analgesic treatment and with one of the following diagnoses - lung cancer, colorectal cancer, breast cancer or prostate cancer, and judged to be in the final stage of life. Furthermore, patients needed to be aware that they had been diagnosed with cancer and would receive PC, as opposed to primarily curative care.

\section{Instruments}

\section{Demographic and clinical characteristics}

A demographic sheet was used to gather data from the patients regarding the following variables: gender, age, civil status, diagnosis, place of care, receiving help, duration of care from PC, prescribed analgesic medication, non-pharmacological pain treatment and the intensity and quality of pain.

\section{Pain assessment}

Pain intensity and pain quality were outcome variables assessed with the help of Pain-O-Meter (POM) together with questions selected from the American Pain Society's Patient Outcome Questionnaire (APS 1995). Pain-OMeter is unique as it provides information about both the intensity and the quality of pain (Gaston-Johansson 1996). In order to indicate pain intensity, POM has a visual ana- 
logue scale (VAS) at the front, a 10-cm straight-line continuum with anchors on each end, representing no pain at the lower end and severe pain at the upper end of the scale. A centimetre scale is located on the reverse side, numbered $0-10$. In order to assess pain quality, POM has a list of 12 sensory and 11 affective word descriptors marked on it. These words represent common pain words. Each word has an assigned intensity value (range 1-5, $1=$ mild pain to $5=$ strong experiences of pain). Both POM and VAS are tested on a variety of patients with different diagnoses, demonstrating satisfactory reliability and validity for assessment of pain intensity and quality (Herr \& Mobily 1993; Gaston-Johansson 1996; Calvin et al. 1999). The five pain items assessing pain intensity and quality were: How much pain are you in right now?; Please indicate the worst pain you have had in the last $24 \mathrm{~h}$; Please indicate the average pain you have had in the last $24 \mathrm{~h}$; Please describe your pain (sensory component); Please describe your feelings toward your pain (affective component).

\section{Pain control in palliative care questionnaire}

A 12-item questionnaire [pain control in palliative care questionnaire (PC-PCQ)] was developed containing two parts with questions about PC related to pain management. Each item had both a before- and during (now with)PC perspective (Table 1). The questionnaire aimed to cover the six dimensions of pain (Ahles et al. 1983; McGuire 1992), the pain management process and the other objectives of PC. The first part comprised nine items regarding the patient's experiences of the care process. The second part comprised three items selected and modified from APS (1995), regarding instructions about pain medication. The questionnaire was aimed to be brief and easy to use in an interview. An explorative factor analysis was carried out resulting in five factors with an eigen value (Burns \& Grove 1997) above 1.0 (cum 62\% of total variance). Factor 1 represented pain control before PC (loadings 0.48-0.77, Cronbach's alpha coefficient 0.44). Factor 2 represented symptom control before and during PC (loadings 0.510.82 , Cronbach's alpha coefficient 0.83 ). Factor 3 represented medication routines during PC (loadings 0.64-0.82, Cronbach's alpha coefficient 0.79 |. Factor 4 represented pain control during PC (loadings 0.59-0.75, Cronbach's alpha coefficient 0.70$)$. Factor 5 represented socio-cultural contacts before and during PC (loadings 0.88-0.91, Cronbach's alpha coefficient 0.87). Cronbach's alpha for the whole questionnaire was found to be 0.76 . Over and above testing for internal consistency reliability, this construct validity test was motivated because by the fact that the questionnaire was new (Streiner \& Norman 2001).

\section{Data collection}

Patients received both written and verbal information about the study; they were asked if they were willing to participate by the PC team staff. Consenting patients were contacted for an interview and again informed that participation was voluntary, that answers would be treated in confidence and that they could withdraw at any time, without reason. The first author, a nurse teacher, especially interested in pain and without any connection to the care teams, collected the data. First the purpose, content and layout of the questionnaire and POM were explained thoroughly to the patients. Then the first author completed the questionnaire as well as the demographic and clinical data by interviewing the patients. Supplementary information about prescribed analgesic medication was obtained from the patients' charts. The patients were also asked to carefully describe their pain using POM, by choosing from each group of sensory and affective words the ones that best described the pain they experienced. Pain intensity was assessed by asking the patients to move the adjustable marker along the line on the front of the POM indicating 'no pain' at the lower end and 'severest possible pain' at the upper end.

\section{Data analyses}

Descriptive statistics were used to describe the demographic and clinical characteristics of the sample. Wilcoxon's Signed-Rank test was used to test for significant changes in score before and during PC. Spearman's correlation coefficient was utilized for assessing correlations among items. Multiple regression analysis was performed to measure the strength of the correlations between independent and dependent variables. The level of statistical significance was calculated to $P<0.05$.

\section{RESULTS}

\section{Characteristics of the patients}

Seventy-five patients managed to complete the demographic, clinical and treatment characteristics, which are summarized in Table 2. After this, one patient was excluded because of weak condition and severe pain. With regard to pain intensity, 22 patients rated current pain as $>3$ on the POM-VAS. Twenty-nine patients reported worst pain in the last $24 \mathrm{~h}$ between 4 and 6 on the POM-VAS, while 18 patients reported worst pain $>6$. The affective and sensory pain words are presented in Figures 1 and 2 and represent the first word each patient used when asked to describe their pain quality. In order to describe their 
Table 1. The recently established questionnaire: pain control in palliative care questionnaire (PC-PCQ)

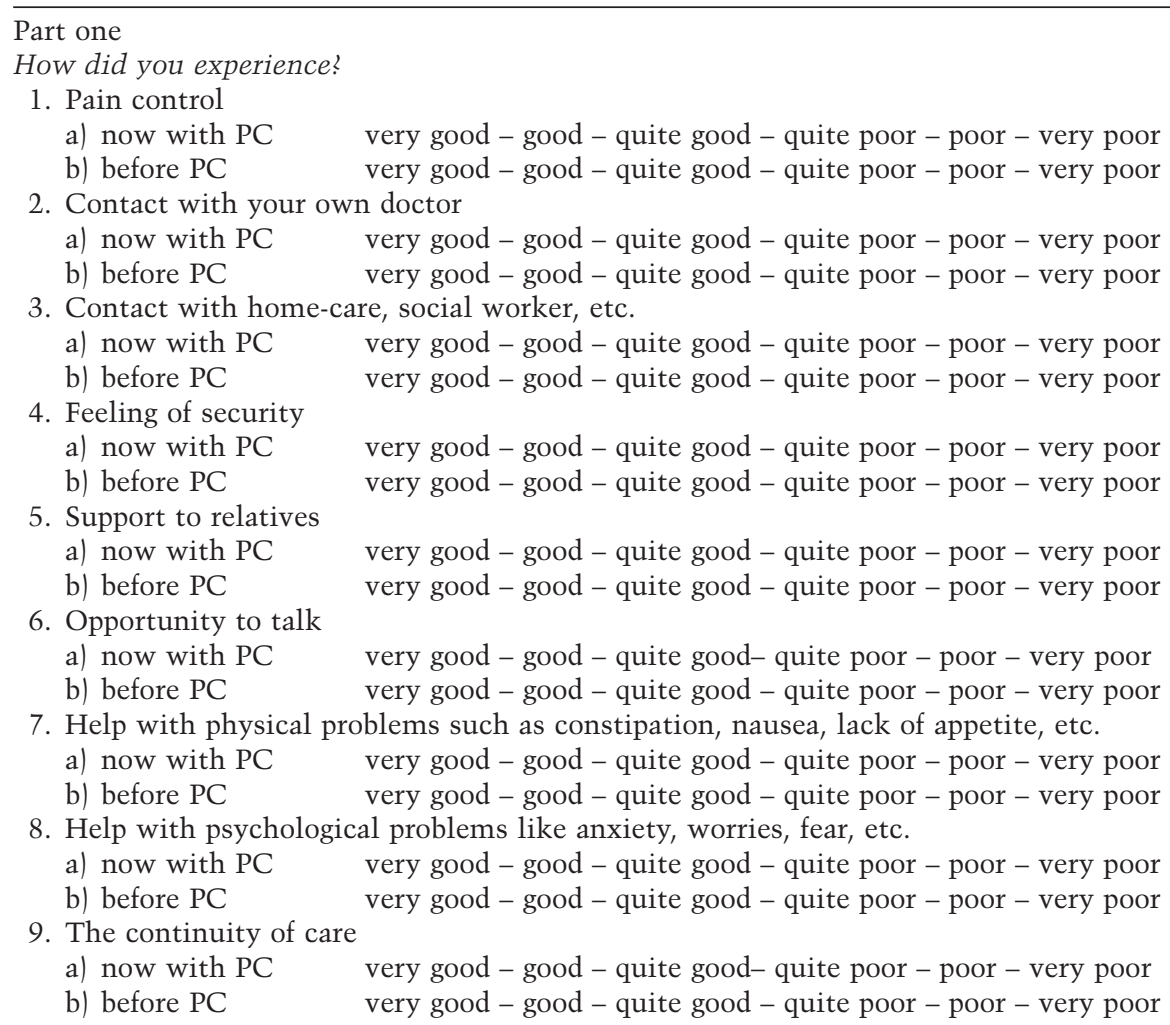

Part two

How clear are the instructions?

10. Schedule for taking pain medications (how much of each and when)

a) now with PC No instructions? - Instructions are unclear to me, or I forgot. - Instructions are fairly clear - Instructions are

b) before PC absolutely clear

No instructions? - Instructions were unclear to me, or I forgot. - Instructions were fairly clear - Instructions were absolutely clear

11. What to do if the current medication schedule does not relieve your pain or produces side-effects (on-demand)
a) now with PC
No instructions? - Instructions are unclear to me, or I forgot. - Instructions are fairly clear - Instructions are absolutely clear
b) before PC
No instructions? - Instructions were unclear to me, or I forgot. - Instructions were fairly clear - Instructions were absolutely clear
12. Who to call about your pain if you have any questions
a) now with PC
No instructions?
absolutely clear
b) before PC
No instructions? - Instructions were unclear to me, or I forgot. - Instructions were fairly clear - Instructions were absolutely clear

PC, palliative care.

affective pain, 24 patients used the words 'troublesome' or 'tiring' and six patients used the words 'torturing', 'killing' or 'suffocating'. Sensory pain was described as 'prickling' or 'sore' by 15 patients and as 'tearing' or 'cutting' by four patients.

\section{The care process before and during palliative care}

Statistically significant $(P<0.01-0.001)$ improvements in care related to pain management after being referred to PC were shown for all items in the questionnaire (Table 3).

\section{The care process during palliative care}

Patients' description of 'pain control' had a statistically significant correlation with their description of 'feeling of security' $(r=0.239, P<0.05)$, with 'continuity of care' $(r=0.279, P<0.05)$ and with 'instructions who to call about your pain if you have any questions' $(r=0.257$, $P<0.05)$ during PC. 'Feeling of security' was the item that provided a statistically significant correlation with all the other items, during PC $(r=0.239, P<0.05$ to $r=0.521$, $P<0.001)$. When selecting 'feeling of security' as a dependent variable using the Stepwise method, two indepen- 
Table 2. Demographic and clinical characteristics for patients with cancer cared for in palliative care $(\mathrm{PC})(n=75)$

\begin{tabular}{|c|c|c|c|c|c|}
\hline & $n$ & Mean & Median & Range & SD \\
\hline \multicolumn{6}{|l|}{ Gender } \\
\hline Men & 52 & & & & \\
\hline Women & 23 & & & & \\
\hline Age (years) & 75 & 70 & 70 & $35-88$ & 10.1 \\
\hline \multicolumn{6}{|l|}{ Civil status } \\
\hline Married or cohabiting & 51 & & & & \\
\hline Single & 24 & & & & \\
\hline \multicolumn{6}{|l|}{ Diagnosis } \\
\hline Breast cancer & 13 & & & & \\
\hline Colorectal cancer & 20 & & & & \\
\hline Lung cancer & 15 & & & & \\
\hline Prostate cancer & 27 & & & & \\
\hline \multicolumn{6}{|l|}{ Place of care } \\
\hline At home & 49 & & & & \\
\hline At hospital & 19 & & & & \\
\hline $\begin{array}{l}\text { Mix of hospital and at } \\
\text { home }\end{array}$ & 7 & & & & \\
\hline \multicolumn{6}{|l|}{ Help from } \\
\hline Relatives & 29 & & & & \\
\hline Home-care & 8 & & & & \\
\hline At hospital & 19 & & & & \\
\hline $\begin{array}{l}\text { Mix of hospital, } \\
\text { relatives and home- } \\
\text { care }\end{array}$ & 7 & & & & \\
\hline No help & 12 & & & & \\
\hline Time with PC (months) & 75 & 3 & 2 & $1-8$ & 1.9 \\
\hline \multicolumn{6}{|l|}{$\begin{array}{l}\text { Pain intensity levels } \\
\text { (rated with visual } \\
\text { analogue scale) }\end{array}$} \\
\hline $\begin{array}{l}\text { Pain at the time of the } \\
\text { interview }\end{array}$ & 75 & 2.6 & 2.0 & $0-8$ & 1.8 \\
\hline Worst pain past $24 \mathrm{~h}$ & 75 & 4.4 & 4.0 & $0-9$ & 2.5 \\
\hline Average pain past $24 \mathrm{~h}$ & 75 & 3.0 & 3.0 & $0-8$ & 1.9 \\
\hline \multicolumn{6}{|l|}{ Analgesics } \\
\hline Strong opioid & 58 & & & & \\
\hline Weak opioid & 4 & & & & \\
\hline NSAID & 20 & & & & \\
\hline Paracetamol & 61 & & & & \\
\hline On-demand analgesics & 57 & & & & \\
\hline \multicolumn{6}{|c|}{ Non-pharmacological treatment } \\
\hline Massage & 1 & & & & \\
\hline Tactile massage & 1 & & & & \\
\hline TENS & 1 & & & & \\
\hline
\end{tabular}

NSAID, non-steroidal anti-inflammatory drugs; TENS, transcutaneous electrical nerve stimulation.

dent variables were statistically significant predictors. 'Opportunity to talk' was the best predictor that accounted for $35 \%$ of the variance $\left(R^{2}=0.35, F=36.43\right.$, $P<0.001)$, while the second predictor 'continuity of care' accounted another $10 \%\left(R^{2}=0.46, F=27.70, P<0.001\right)$.

\section{DISCUSSION}

With regard to the applicability of the study findings, the following should be considered: the study was performed on a small sample of patients with advanced cancer, already referred to PC. The PC staff selected patients con-

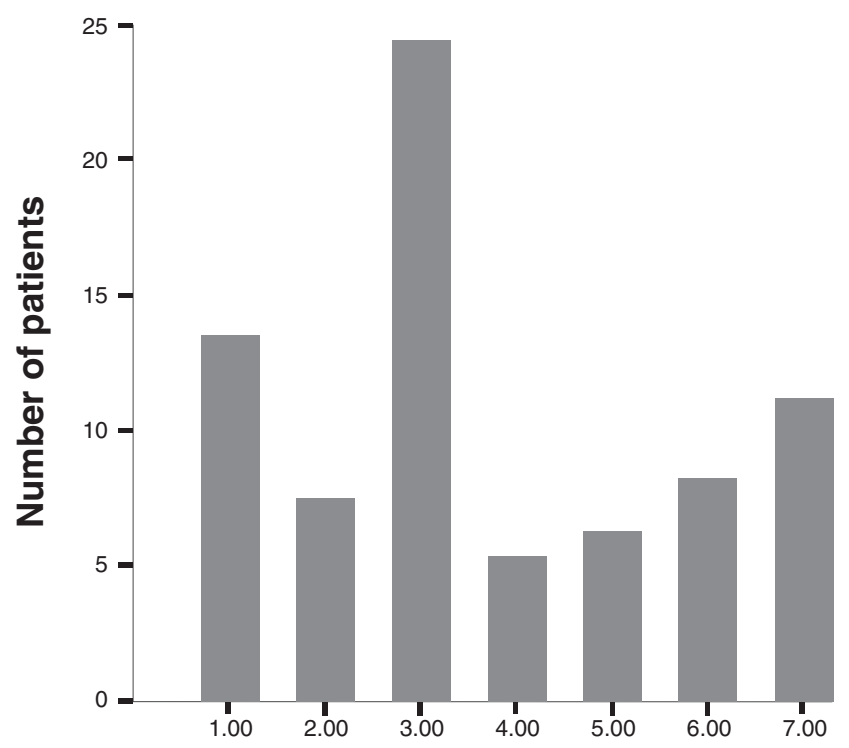

\section{Affective pain words}

Figure 1. Affective pain descriptors expressed by patients with cancer and during palliative care. $1=$ worrying; $2=$ irritating; $3=$ troublesome, tiring; $4=$ terrifying, unbearable; $5=$ torturing, killing, suffocating, dreadful, excruciating; $6=$ patients who used own words; 7 = patients who could not express an affective word (Gaston-Johansson 1996).

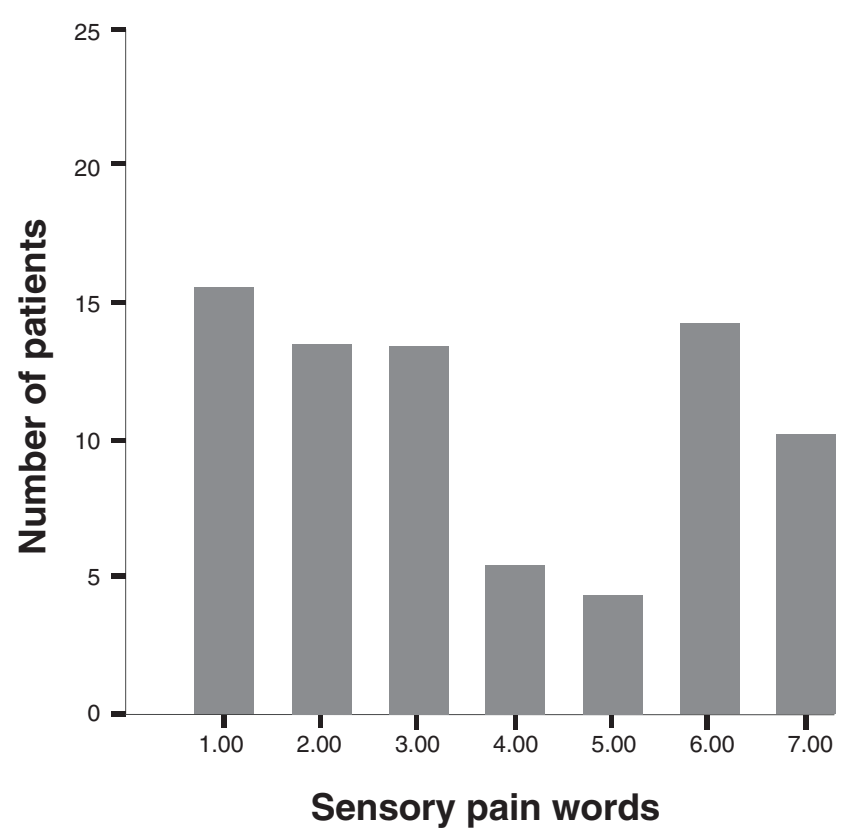

Figure 2. Sensory pain descriptors expressed by the patients with cancer and during palliative care. 1 = prickling, sore $2=$ pinching, nagging, teasing; $3=$ aching, gnawing; $4=$ cramping, pressing, burning; 5 =tearing, cutting; 6 = patients who used own words; $7=$ patients who could not express a sensory word (GastonJohansson 1996). 
Table 3. Differences, from the questionnaire describing cancer patients' experiences of care before and now with palliative care (PC) $(n=75)$ (Wilcoxon's Signed-Ranks test)

\begin{tabular}{|c|c|c|c|}
\hline Item $(n)$ & $\begin{array}{l}\text { Before PC } \\
\text { Median (range) }\end{array}$ & $\begin{array}{l}\text { With PC } \\
\text { Median (range) }\end{array}$ & $P$-value \\
\hline Pain control $(n=73)$ & $\begin{array}{l}\text { Quite poor } \\
\text { (good - very poor) }\end{array}$ & $\begin{array}{l}\text { Good } \\
\text { (very good - quite poor) }\end{array}$ & $<0.001$ \\
\hline $\begin{array}{l}\text { Contact with home- } \\
\text { care, social } \\
\text { worker, etc. } \\
(n=50)\end{array}$ & $\begin{array}{l}\text { Quite poor } \\
\text { (good - very poor) }\end{array}$ & $\begin{array}{l}\text { Good } \\
\text { (very good - very poor) }\end{array}$ & $<0.001$ \\
\hline $\begin{array}{l}\text { Feeling of security } \\
(n=72)\end{array}$ & $\begin{array}{l}\text { Quite poor } \\
\text { (good - very poor) }\end{array}$ & $\begin{array}{l}\text { Good } \\
\text { (very good - very poor) }\end{array}$ & $<0.001$ \\
\hline $\begin{array}{l}\text { Support to relatives } \\
\qquad(n=60)\end{array}$ & $\begin{array}{l}\text { Quite poor } \\
\text { (very good - very poor) }\end{array}$ & $\begin{array}{l}\text { Quite good } \\
\text { (very good - poor) }\end{array}$ & $<0.001$ \\
\hline $\begin{array}{l}\text { Opportunity to talk } \\
(n=71)\end{array}$ & $\begin{array}{l}\text { Quite poor } \\
\text { (very good - very poor) }\end{array}$ & $\begin{array}{l}\text { Good } \\
\text { (very good - poor) }\end{array}$ & $<0.001$ \\
\hline $\begin{array}{l}\text { Continuity of care } \\
(n=72)\end{array}$ & $\begin{array}{l}\text { Quite poor } \\
\text { (good - very poor) }\end{array}$ & $\begin{array}{l}\text { Good } \\
\text { (very good - poor) }\end{array}$ & $<0.001$ \\
\hline $\begin{array}{l}\text { Schedule pain } \\
\text { medication } \\
(n=74)\end{array}$ & $\begin{array}{l}\text { No instructions } \\
\text { (no instructions - absolutely clear instructions) }\end{array}$ & $\begin{array}{l}\text { Absolutely clear instructions } \\
\text { (no instructions - absolutely clear instructions) }\end{array}$ & $<0.001$ \\
\hline $\begin{array}{l}\text { On-demand pain } \\
\text { medication } \\
(n=74)\end{array}$ & $\begin{array}{l}\text { No instructions } \\
\text { (no instructions - absolutely clear instructions) }\end{array}$ & $\begin{array}{l}\text { Absolutely clear instructions } \\
\text { (no instructions - absolutely clear instructions) }\end{array}$ & $<0.001$ \\
\hline Who to call $(n=74)$ & $\begin{array}{l}\text { No instructions } \\
\text { (no instructions - absolutely clear instructions) }\end{array}$ & $\begin{array}{l}\text { Absolutely clear instructions } \\
\text { (no instructions - absolutely clear instructions) }\end{array}$ & $<0.001$ \\
\hline
\end{tabular}

secutively and asked for verbal consent at a suitable opportunity depending on the patient's condition. Although this may be a limitation of the study, it could also explain why there were no dropouts when the patients were contacted for their interview. Notably, the sample was biased in favour of men. To what extent this has influenced the outcome is unknown, but according to Gordin et al. (2001) it may be a disturbing pattern, as women tend to have their cancer pain undertreated more frequently than men. The reliability is debatable, as the patients were asked to recall their experiences of care from memory from the time preceding PC referral. Nevertheless, the strong concordance in the answers both before and during (now with) PC is worth noting as well, as all patients appeared to have a clear recollection of the time they got in touch with PC. One could argue that reliability might have been improved if patients had been interviewed at least twice, before and during PC. In reality, however, conducting research with patients during PC is the only viable solution. Prior to PC referral, patients are often in pain and in a very weak condition making it difficult to ask them to participate and casting doubt over a truly informed consent (Daniels \& Exley 2001). And, as deaths are to be expected for this group of patients, followup data collection would be incomplete (McMillan 1996). This study was performed specially in order to reduce data collection problems and the questionnaire was designed to limit data collection to one convenient occasion immediately after patients' referral to PC. The whole questionnaire showed good reliability in terms of Cronbach's alpha (0.76). Accordingly, the questionnaire showed sufficient construct validity, considering it is a recently developed questionnaire, if used as a current measurement tool as in this study (Streiner \& Norman 2001). With regard to content validity, the questionnaire along with measurement of pain quality and intensity covers all pain dimensions (Ahles et al. 1983; McGuire 1992; Ferrell et al. 1994; Mino 1999) and PC objectives. It can be difficult to obtain unbiased answers if the researcher is involved in the patients' care (Miaskowski et al. 1994; Daniels \& Exley 2001), therefore, the author who interviewed the patients assured them that none of their answers would influence the care they were receiving, thereby providing the study with sufficient objectivity.

The sensory and physiological dimensions of pain are amply covered, as the cancer-diagnosed patients were 
questioned about both pain intensity and experience of pain control. The median and mean ratings of current and average pain intensities were acceptable (Table 2), but still there were patients who described suffering too much pain. Despite unacceptably high worst-pain levels the patients described 'pain control' during PC as good. One interpretation is that the patients were unable to distinguish between an overall better care and pain control (Miaskowski et al. 1994; Boström et al. 1997). Pain medication had obviously been optimized during PC, with the result that almost all patients said that the analgesic medication instructions were perfectly clear (Table 3). Clear instructions for 'pain medication' and 'who to call' are aspects included in the behavioural dimension of pain. The discrepancy between high pain intensities and statements of clear instructions indicates that some patients may not have followed the instructions or avoided asking for more pain medication despite knowing 'who to call'. Patients' compliance with scheduled analgesics or use of on-demand analgesics was only based on the prescriptions made; no evaluation of patients' actual intake was made. Furthermore, on-demand analgesics were not prescribed for 17 of the patients (Table 2). Ahles et al. (1983) found that the use of pain medication correlated with sensory, cognitive and affective dimensions of pain, specifically linked with the experiences of pain. The frequent expressions of pain as 'worrying' and 'troublesome' (Fig. 1) and the many patient reports of unacceptable worst-pain levels could imply that some patients dared not admit to increasing pain levels. Perhaps this was because of thoughts concerning the source, meaning and course of the disease. This may be a lack of inventing the cognitive dimension of pain (Calvin et al. 1999). The correlation between 'pain control', 'feeling of security' and 'continuity of care' during PC revealed a further correlation between pain dimensions, and between sensory, affective and socio-cultural dimensions of pain. Coupled with the fact that 'opportunity to talk' appeared to be the strongest predictor for 'feeling of security', this enforces the importance of considering the cognitive dimension of pain (Calvin et al. 1999). 'Support to relatives' is included in the socio-cultural dimension of pain. Probably most of the patients had understood this question as 'support to next of kin' as 24 patients lived alone (Table 2), explaining the 14 internal dropouts (Table 3).

Patients' experiences of care before PC showed a range from good to very poor and a lack of instructions over how to handle pain (Table 3). In line with Newbury (2002), this study showed increased help with physical and psychological problems such as nausea, constipation, anxiety or worries during PC. However, the many internal dropouts for these items, compared with no internal dropouts for the item 'pain control' (Table 3), probably result from pain being the most common problem (Ellershaw et al. 1995). The improvement of other symptoms suggests a further benefit of increased pain control (Ellershaw et al. 1995; Holzheimer et al. 1999). The increased 'pain control' may also have been a result of patients' opportunity to discuss their understanding of the situation, also allowing them to collect further information (Ellershaw et al. 1995; Milberg \& Strang 2000). The correlations between 'pain control', 'feeling of security' and 'opportunity to talk' during PC could provide such indications. The fundamental importance of communication as well as taking time to talk with the patients has been stressed and is considered central to nursing in PC. Supported by the American Pain Society guidelines (APS 1995), it is suggested that inadequate communication often contributes to suboptimal pain management. Nurses have to facilitate patients and their families to engage in decision-making over a wide range of issues in PC from goals for treatment to where to stay. For the 49 patients who stayed at home (Table 2) maintaining 'continuity of care' was the responsibility of the nurse. The importance of 'continuity of care' and clear instructions about 'who to call' contributing to 'feeling of security' was revealed in this study and is supported by Milberg \& Strang (2000). It would appear, however, that interventions for treatment need improving, as only three patients stated that they had received a non-pharmacological intervention (Table 2). According to the guidelines from The Swedish Nurse organization (1999), nurses urge implementation of interventions such as massage, cold and heat, distraction techniques and transcutaneous electrical nerve stimulation (TENS) in pain management. Ferrell et al. (1994) found that both patients and their families considered the non-pharmacological pain treatment important in addition to analgesic treatment. Clearly, while pain management in PC requires a multidimensional approach it also needs to be performed by a multidisciplinary team in which the nurse ought to have a key function (Ferrell et al. 1994; The Swedish National Board of Health \& Welfare 2001). Nursing care of patients with pain and in PC must include open and improved communication not only with the patients and their families, but also with the patients' physician and other health care providers.

\section{CONCLUSION}

Cancer patients in pain benefited from PC despite the fact that the pain control provided had not been optimized. 'Continuity of care' and 'opportunity to talk' increases the 
patient's 'feeling of security', which is of utmost importance for successful pain management in PC. Pain control is not only dependent upon analgesic treatment but also on the many other aspects of care provided by the nurse. The findings supported the need for a multidimensional approach to pain management in PC, although it is impossible to distinguish clearly between the different dimensions of pain. As many patients reported severe worst pain during the past $24 \mathrm{~h}$, patients' compliance with the analgesic treatment needs to be studied further. Therefore, more research and clinical efforts must be applied to explore the cognitive dimension of pain. Furthermore, a complement of non-pharmacological treatments would be of value if implemented within the provision of PC service.

\section{REFERENCES}

Abu-Saad H. (2000) Palliative care: an international view. Patient Education and Counseling 41, 15-22.

Ahles T., Blanchard E. \& Ruckdeschel J. (1983) The multidimensional nature of cancer-related pain. Pain 17, 277-288.

American Pain Society Quality of Care Committee (APS) (1995) Quality improvement guidelines for the treatment of acute pain and cancer pain. Journal of the American Medical Association 274, 1874-1880.

Ashby M. \& Dowding C. (2001) Hospice care and patients' pain: communication between patients, relatives, nurses and doctors. International Journal of Palliative Nursing 7, 58-67.

Boström B., Ramberg T., Davis B. \& Fridlund B. (1997) Survey of post-operative patients' pain management. Journal of Nursing Management 5, 341-349.

Burns N. \& Grove S. (1997) The practice of nursing research. Conduct, Critique and Utilization, 3rd edn. W.B. Saunders, Philadelphia, PA, USA.

Calvin A., Becker H., Biering P. \& Grobe S. (1999) Measuring patients opinion of pain management. Journal of Pain and Symptom Management 17, 17-26.

Chochinov H. \& Kristjanson L. (1998) Dying to pay: the cost of end-of-life care. Journal of Palliative Care 14, 5-15.

Daniels L. \& Exley C. (2001) Preparation, information and liaison: conducting successful research in palliative care. International Journal of Palliative Nursing 7, 192-197.

Ellershaw J., Peat S. \& Boys L. (1995) Assessing the effectiveness of hospital palliative care team. Palliative Medicine 9, 145-152.

Ferrell B., Ferrell B., Ahn C. \& Tran K. (1994) Pain management for elderly patients with cancer at home. Cancer 74, 2139-2146.

Gaston-Johansson F. (1996) Measurement of pain: the psychometric properties of the Pain-O-Meter, a simple inexpensive pain assessment tool that could change health care practices. Journal of Pain and Symptom Management 3, 172-181.

Gordin V., Weaver M.A. \& Hahn M.B. (2001) Acute and chronic pain management in palliative care. Best Practice and Research Clinical Obstetrics and Gynaecology 15, 203-234.

Hearn J. \& Higginson I. (1998) Do specialist palliative care teams improve outcomes for cancer patient? A systematic literature review. Palliative Medicine 12, 317-332.

Hearn J. \& Higginson I. (1999) Development and validation of a core outcome measure for palliative care: the palliative care outcome scale. Quality in Health Care 8, 219-227.

Herr K. \& Mobily P. (1993) Comparison of selected pain assessment tools for use with the elderly. Applied Nursing Research 6, 39-46.

Holzheimer A., McMillan S. \& Weitzner M. (1999) Improving pain outcomes of hospice patients with cancer. Oncology Nursing Forum 26, 1499-1504.

Ingleton C., Field D. \& Clark D. (1997) Multidisciplinary case study as an approach to the evaluation of palliative care services: two examples. International Journal of Palliative Nursing 3, 335-339.

McGuire D.B. (1992) Comprehensive and multidimensional assessment and measurement of pain. Journal of Pain and Symptom Management 7, 312-319.

McMillan S. (1996) Pain and pain relief experienced by hospice patients with cancer. Cancer Nursing 19, 298-307.

McWhinney I.R., Bass M.J. \& Donner A. (1994) Evaluation of palliative care service: problems and pitfalls. British Medical Journal 309, 1340-1342.

Miaskowski C., Nichols R., Brody R. \& Synold T. (1994) Assessment of pain satisfaction utilizing the American Pain Society's quality assurance standards an acute and cancer-related pain. Journal of Pain and Symptom Management 9, 5-11.

Milberg A. \& Strang P. (2000) Met and unmet needs in hospitalbased home care: qualitative evaluation through open-ended questions. Palliative Medicine 14, 533-534.

Mino J. (1999) Assessing the outcome of palliative care. European Journal of Palliative Care 6, 203-205.

Newbury J. (2002) Symptom control outcomes in a community palliative care nursing team. International Journal of Palliative Nursing 8, 6-12.

Rink G.C., Geertrudis A.M., Kleijen J., Hanneke J.C.J.M., Schade E. \& Veenhof C.H.N. (1997) Methodological issues in effectiveness research on palliative cancer care: a systematic review. Journal of Clinical Oncology 15, 1697-1707.

Strang P. (1998) Cancer pain - a provoker of emotional, social and existential distress. Acta Oncologica 37, 641-644.

Streiner D. \& Norman G. (2001) Health Measurement Scales. A practical guide to their development and use, 2nd edn. Oxford Medical Publications, Oxford.

The Swedish National Board of Health and Welfare (2001) Pain Management at the End of Life. Guidelines. Socialstyrelsen, Stockholm, Sweden (in Swedish).

The Swedish Nurse Organisation (1999) Cancer-Related Pain. Guidelines for pain management, patient education and complementary pain management. SSF, SPRI, Stockholm, Sweden (in Swedish).

Thomason T., McCune S., Bernard S., Winer E., Tremont S. \& Lindley C. (1998) Cancer pain survey: patients-centred issues in control. Journal of Pain and Symptom Management 15, 275284.

Twycross R., Harcourt J. \& Bergl S. (1996) A survey of pain in patients with advanced cancer. Journal of Pain and Symptom Management 12, 273-282.

World Health Organization (1996) Cancer Pain Relief: With a Guide to Opioid Availability, 2nd, edn. WHO, Geneva. 